\title{
Relationship between healthcare seeking and pain expansion in patients with nonspecific chronic low back pain
}

\author{
Mónica Grande-Alonso ${ }^{1,2}$, Daniel Muñoz-García ${ }^{1,2}{ }$, Ferran Cuenca-Martínez ${ }^{1,2}$, Laura Delgado-Sanz ${ }^{1}$, María \\ Prieto-Aldana $^{1,2}$, Roy La Touche ${ }^{\text {Corresp., 1, 2, 3,4 }}$, Alfonso Gil-Martínez ${ }^{1,4,5}$ \\ ${ }^{1}$ Departamento de Fisioterapia. Centro Superior de Estudios Universitarios La Salle, Universidad Autónoma de Madrid, Madrid, Spain \\ 2 Motion in Brains Research Group, Institute of Neuroscience and Sciences of the Movement (INCIMOV), Centro Superior de Estudios Universitarios La \\ Salle, Universidad Autónoma de Madrid, Madrid, Spain \\ 3 Instituto de Neurociencia y Dolor Craneofacial (INDCRAN), Madrid, Spain \\ 4 Instituto de Investigación Sanitaria del Hospital Universitario La Paz (IdiPAZ), Madrid, Spain \\ ${ }^{5}$ CranioSPain Research Group, Departamento de Fisioterapia, Centro Superior de Estudios Universitarios La Salle. Universidad Autónoma de Madrid, \\ Madrid, Spain \\ Corresponding Author: Roy La Touche \\ Email address: roylatouche@lasallecampus.es
}

Objectives: Low back pain (LBP) is the most prevalent musculoskeletal problem, which implies a high rate of chronicity. The chronicity of symptoms can lead to pain expansion. The main objective of this study was to assess whether there were differences between patients with nonspecific chronic LBP (CLBP) who sought healthcare compared to those who did not in terms of pain expansion. Methods: Ninety individuals participated in the study and were divided into 3 groups: 30 patients who sought care; 30 patients who did not seek care; and 30 asymptomatic individuals. The primary variable analyzed was pain expansion. Secondary physical and psychological variables were assessed later, and a regression analysis was performed. Results: Patients who sought help showed significant differences in pain expansion and pain intensity compared with the group who did not seek help, with a medium effect size (0.50-0.79). The regression model for the care-seeking group showed that dynamic balance with the left leg and depression were predictors of percentage pain surface area (34.6\%). The combination of dynamic balance, range of movement in flexoextension and depression were predictors of widespread pain (48.5\%). Conclusion: Patients whosoughtcare presented greater pain expansion than patients whodidnot. A combination of functional and psychological variables can significantly predict pain expansion in patients with nonspecific CLBP who seek help. 


\section{Relationship between healthcare seeking and pain expansion in patients with}

\section{2 nonspecific chronic low back pain}

3 Mónica Grande-Alonso ${ }^{1,2}$, Daniel Muñoz-García ${ }^{2}$, Ferran Cuenca-Martínez ${ }^{1,2}$, Laura Delgado-

4 Sanz $^{1}$, María Prieto-Aldana ${ }^{1,2}$, Roy La Touche ${ }^{1-4^{*}}$, Alfonso Gil-Martínez ${ }^{1,4,5}$

5

1. Departamento de Fisioterapia. Centro Superior de Estudios Universitarios La Salle, Universidad Autónoma de Madrid. Aravaca, Madrid. Spain.

2. Motion in Brains Research Group, Institute of Neuroscience and Sciences of the Movement (INCIMOV), Centro Superior de Estudios Universitarios La Salle, Universidad Autónoma de Madrid, Spain., Madrid, Spain.

3. Instituto de Neurociencia y Dolor Craneofacial (INDCRAN), Madrid, España.

4. Instituto de Investigación Sanitaria del Hospital Universitario La Paz (IdiPAZ), Madrid, España.

5. CranioSPain Research Group, Departamento de Fisioterapia, Centro Superior de Estudios Universitarios La Salle. Universidad Autónoma de Madrid, Aravaca, Madrid, Spain.

\section{*Corresponding author:}

Roy La Touche

Address: Facultad de Ciencias de la Salud

Centro Superior de Estudios Universitarios La Salle

Calle La Salle, n 10, 28023 Madrid, Spain

Telephone: (+34) 917401980 Fax: (+34) 913571730

E-Mail: roylatouche@yahoo.es 
26 Disclosure statement: The authors declare that they have no conflicts of interest. This research

27 did not receive any specific grant from funding agencies in the public, commercial, or not-for28 profit sectors. 
29 ABSTRACT

30 Objectives: Low back pain (LBP) is the most prevalent musculoskeletal problem, which implies

31 a high rate of chronicity. The chronicity of symptoms can lead to pain expansion. The main

32 objective of this study was to assess whether there were differences between patients with nonspecific chronic LBP (CLBP) who sought healthcare compared to those who did not in terms of pain expansion.

Methods: Ninety individuals participated in the study and were divided into 3 groups: 30 patients who sought care; 30 patients who did not seek care; and 30 asymptomatic individuals. The primary variable analyzed was pain expansion. Secondary physical and psychological variables were assessed later, and a regression analysis was performed.

Results: Patients who sought help showed significant differences in pain expansion and pain intensity compared with the group who did not seek help, with a medium effect size $(0.50-0.79)$. The regression model for the care-seeking group showed that dynamic balance with the left leg and depression were predictors of percentage pain surface area $(34.6 \%)$. The combination of dynamic balance, range of movement in flexoextension and depression were predictors of widespread pain $(48.5 \%)$.

Conclusion: Patients who sought care presented greater pain expansion than patients who did not.

A combination of functional and psychological variables can significantly predict pain expansion

47 in patients with nonspecific CLBP who seek help.

Keywords: Chronic pain, Chronic widespread pain, Psychosocial factors, Pain expansion 
51

52

53

54

55

56

57

\section{INTRODUCTION}

Low back pain (LBP) is the most prevalent musculoskeletal problem and the fourth pathological cause of disability, which implies a high rate of chronicity and absenteeism (Hoy et al., 2012). Between $13.5 \%$ and $47 \%$ of the general population has been found to have chronic musculoskeletal pain (Cimmino, Ferrone, \& Cutolo, 2011). Chronic pain is defined as pain that persists beyond 6 months, leading to neural, somatic, cognitive and behavioral disturbances. Such alterations can lead to maladaptive neuroplastic changes at the medullary and supramedullary level (Hashmi et al., 2013; Merskey, H; Bogduk, 1994; Walsh et al., 2008), associated with the concept of nociplastic pain. Such pain is defined, according to the International Association for the Study of Pain, as "pain that arises from altered nociception despite no clear evidence of actual or threatened tissue damage causing the activation of peripheral nociceptors or evidence for disease or lesion of the somatosensory system causing the pain" (IASP, 2017).

Among the characteristics found in this population, it has been observed that individuals with chronic low back pain (CLBP) can present functional alterations, such as changes in dynamic stability or range of motion, physical alterations and somatosensory disturbances (Sadler, Spink, Ho, De Jonge, \& Chuter, 2017; Laird, Gilbert, Kent, \& Keating, 2014; Tong et al., 2017). All these characteristics make CLBP a major public health problem, given it causes major disability and a reduction in quality of life of those who experience it. However, the prevalence of health system use in Europe for LBP has been shown to be low, at 48\% (Beyera, Brien, \& Campbell, 2019). Thus, numerous studies have evaluated the factors that lead a patient with CLBP to seek professional help (Buchan, Duggan, Hargreaves, Scott, \& Slawomirski, 2016; IJzelenberg \& Burdorf, 2004; Traeger, Buchbinder, Elshaug, Croft, \& Maher, 2019). Research has shown that there is a positive association between care seeking and sociodemographic variables such as age, 
74 as well as other variables related to the experience of pain, such as pain intensity, frequency of

75 pain episodes, disability and chronicity of symptoms and cognitive variables (Jacob, Zeev, \& Epstein, 2003; Mannion, Wieser, \& Elfering, 2013; Szpalski, Nordin, Skovron, Melot, \& Cukier, 1995) Similarly, although some care-seeking patients have been shown to develop an external locus of control, high rates of disability and a greater influence of psychological factors in regard to their perception of pain, no studies have shown how these relate to care seeking for pain expansion (Ferreira et al., 2010; Rollman, A., Visscher, C. M., Gorter, R. C., \& Naeije, 2012; Rollman, A., Gorter, R.C., Visscher, C.M., \& Naeije, M.M, 2013).

CWP is defined as pain present on both sides of the body, involving an expansion to the upper limbs, the lower limbs and the axial skeleton (Wolfe et al., 1990). CWP is an important clinical variable because it provides us with abundant information. This condition has been shown to have a high impact on functionality, quality of life and psychological factors (Landmark et al., 2013; Papageorgiou, Silman, \& Macfarlane, 2002). Reis et al. had studied brain regions related to emotions and cognition in patients with chronic pain and found that changes in brain function are related to CWP in various regions of the body (Reis et al., 2018). In particular, CWP was associated with high rates of anxiety and depression, but evidence is still scarce (Hagen, Linde, Heuch, Stovner \& Zwart, 2011; Ris et al., 2019).

The main objective of this study was to assess whether there were differences between patients with nonspecific CLBP who sought health care compared with those who did not, in terms of pain expansion. The secondary objective was to determine which factors predictive of greater pain expansion are present in patients with nonspecific CLBP based on their search for care.

\section{Design and Sample}


97 This study was cross-sectional with a non-probabilistic sample, with the aim of assessing 98 somatosensory, physical and psychosocial variables in patients with nonspecific CLBP who seek

99

100

101

102

103

104

105

106

107

108

109

110

111

112

113

114

115

116

117

118 care or not and asymptomatic individuals. The trial was conducted in accordance with the Strengthening the Reporting of Observational Studies in Epidemiology statement (von Elm et al., 2008). Following the Helsinki Declaration, the local Ethics Committee approved our study (PI2567) for clinical research in a public reference hospital in Madrid (Spain), and written informed consent was obtained from all participants.

The participants were recruited between April 2017 and January 2018. The sample was recruited from our university campus and the local community through flyers, posters, social media and outpatients of a primary healthcare center in Madrid, Spain.

A consecutive nonprobabilistic convenience sample of 90 individuals was recruited. Participants were classified into the following groups: group 1 was composed of 30 patients with nonspecific CLBP who did not seek care; group 2 was composed of 30 patients with nonspecific CLBP who sought care; and group 3 was composed of 30 asymptomatic individuals. The symptomatic participants were assigned to one group or the other according to whether they sought care from a health professional for their musculoskeletal condition. Those patients who at no time went to any health professional for their problem were classified in the non-care-seeking group. These patients were recruited via flyers placed at the university center and in the local community. The patients who had gone to a primary care doctor due to the presence of CLBP were assigned to the careseeking group, given they had an intention to be treated.

Patients with nonspecific CLBP were selected if they met the inclusion criteria defined by the National Institute for Health and Care Excellence in the LBP Guidelines defines the nature of LBP 
119 as "Tension, soreness and/or stiffness in the lower back region for which it is not possible to

120 identify a specific cause of the pain. Several structures in the back, including the joints, discs and

121 connective tissues, may contribute to symptoms" (Savigny, Watson, \& Underwood, 2009). The

122 following inclusion criteria were also considered on the basis of a previous investigation (Grande-

123 Alonso et al., 2019): (a) LBP for at least the prior 3 months; (b) LBP of a nonspecific nature; (c)

124 men and women aged 18 to 65 years (Carmona, Ballina, Gabriel, \& Laffon, 2001); (d) LBP for at

125 least 10 days per month (Goubert, Danneels, \& Graven-nielsen, 2017); the time between seeking

126 care and recruitment was 5-7 days; and (e) an intensity of pain between 3 and 10 on the visual

127 analogue scale (VAS).

128 Individuals were excluded if they met any of the following exclusion criteria: (a) comorbidities,

129 such as the presence of neurological signs (e.g., weakness perceived in the lower limbs), systemic

130 rheumatic disease (including fibromyalgia) or central nervous system disease; (b) the presence of

131 psychiatric diagnosis or severe cognitive impairment; (c) illiteracy; (d) understanding or

132 communication difficulties; and (e) insufficient Spanish language comprehension to follow 133 measurement instructions.

134 Finally, asymptomatic individuals were excluded if they had a history of spinal pain, another 135 condition of chronic pain or had a diagnosis of any systemic disease.

\section{Procedure}

137 After consenting to participate, all the participants received a sociodemographic questionnaire to 138 complete on the day of the measurement, which collected sex, date of birth and educational level.

139 Next, each participant completed a set of self-report measures, and we evaluated the pain drawings

140 in both the care-seeking and non-care-seeking groups. 
141 Next, the evaluator conducted a semi-structured interview with each of the patients in which

142 questions were asked about their symptomatology (e.g., intensity, frequency and severity of

143 symptoms), demographics and certain questions to determine whether they were in search of

144 treatment, based on previous literature (Macfarlane, TV; Blinkhorn, AS; Davies, RM; Kincey, J;

145 Worthington, 2003; Rollman, A., Gorter, R.C., Visscher, C.M., \& Naeije, M.M, 2013). Once the

146 questionnaires were completed, the participant painted the regions of pain on the body chart. Then,

147 according to the procedure of Dos Reis et al, we used an electronically scanned version of the body

148 diagram and open-source software to calculate the total body area in each pain diagram (F. J. Dos

149 Reis, de Barros E Silva, de Lucena, Mendes Cardoso, \& Nogueira, 2016). Based on the literature,

150 we decided to calculate the percentage pain surface area (PPSA) and count the number of pain

151 sites in order to evaluate widespread pain (WP) (Dragioti, Larsson, Bernfort, Levin, \& Gerdle,

152 2017; Hägg et al., 2003; Persson, Garametsos, \& Pedersen, 2011; Visser, Ramachenderan, Davies,

$153 \&$ Parsons, 2014). A previous study of patients with chronic pain (Muñoz-García et al., 2016) had

154 shown that both PPSA and WP measures were helpful when assessing pain behavior. The PPSA

155 shows the percentage surface area of pain and the WP calculates how widespread that magnitude

156 is (in number of sites) over the body surface area.

157 Finally, a physiotherapist instructed the patients regarding the physical test to be performed, and

158 they were supervised during the session. The first test that was performed was an evaluation of the

159 range of movement in flexoextension (ROMFE) and lateral flexion movements (ROMLF). The

160 protocol for measuring range of motion consisted of the following process: the patient was placed

161 in a standing position with arms along the body; the physiotherapist marked the spinous process

162 of T12 and S2 to place the mobile device; the patient was then asked to perform a maximum trunk

163 flexion (Bedekar, Suryawanshi, Rairikar, Sancheti, \& Shyam, 2014), followed by a maximum 
164 trunk extension. Three measurements were taken, and the average of the differences presented

165 between the two reference points was calculated. Then, the physiotherapist added the degrees of

166 flexion and extension movements. Finally, the patient was placed in the same position with the

167 mobile device placed on T12, the movement of the complete lateral flexion being evaluated

168 (Bedekar et al., 2014).

169 The final test that was performed was the evaluation of dynamic balance by means of the $\mathrm{Y}$

170 Balance Test (YBT). This test was performed in a single-limb stance while simultaneously moving

171 the nonstanding limb in 3 different directions: anteriorly, posteromedially and posterolaterally

172 (Plisky et al., 2009; Teyhen et al., 2014). The composite reach distance (\%) was calculated by the

173 sum of the 3 reach directions divided by 3 times the limb length per 100 (Shaffer et al., 2013).

174 These measurements were obtained for the right and left sides.

\section{Outcome Measures}

\section{Primary variable}

\section{Pain drawings}

178 Pain drawings (PPSA and WP) were assessed using open-source software to calculate the total

179 body area in each pain diagram (Dos Reis, de Barros E Silva, de Lucena, Mendes Cardoso, \&

180 Nogueira, 2016), which has been shown to have good intrarater reliability with an intraclass

181 correlation coefficient $(\mathrm{ICC})=0.99 ; 95 \%$ confidence interval $(\mathrm{CI})=0.98$ to $0.99 ; \mathrm{P}<0.001$. The

182 inter-rater reliability for the measurement was $\mathrm{ICC}=0.989 ; 95 \% \mathrm{CI}=0.980$ to $0.994 ; \mathrm{P}<0.001$

183 (Dos Reis et al., 2016).

\section{Secondary variables}


185

186

187

188

189

190

191 (Grande-Alonso et al., 2019).

192 Frequency of medication

193 The frequency of medication was evaluated based on the number of days the patient had taken

194 medication for LBP in the last month (Grande-Alonso et al., 2019).

195 Level of physical activity

196 The physical activity (PA) level was measured using the International Physical Activity

197 Questionnaire in its short version. It consists of 9 items that quantify the time that the individual 198

205

206
Dynamic balance

devotes to perform any PA of vigorous or moderate intensity. This questionnaire presents an ICC of $0.76(95 \% \mathrm{CI})$ (Craig et al., 2003).

Range of motion

The range of motion was evaluated with a digital inclinometer based on the mobile application, iHandy. It has been shown to have good intrarater and inter-rater reliability, with ICC over 0.80 (95\% CI) (Kolber et al., 2013).

Dynamic balance was measured using YBT. The YBT has shown good to excellent intrarater (0.85-0.91) and inter-rater (0.99-1.00) reliability (Plisky et al., 2009).

Peer] reviewing PDF | (2019:08:40707:2:0:CHECK 5 Feb 2020) 
207

208

209

210

211

212

213

214

215

216

217

218

219

220

221 $222 \&$ Fairbank, 2000).

\section{Sample Size}

22

225

226

227

Anxiety and depression

\section{Fear of movement}

Low back disability

Aanxiety and depression levels were assessed using the Hospital Anxiety and Depression Scale (HADS). The scale has two subscales of 7 items each that measure anxiety and depression (De Las

Cuevas-Castresana, García-Estrada Pérez, \& Gónzalez de Rivera, 1995). The HADS presented an internal consistency (Cronbach's alpha) from 0.80 to 0.93 for the anxiety and 0.81 to 0.90 for the depression subscales (Herrmann, 1997).

Fear of movement was assessed using the 11-item Spanish version of the Tampa Scale of Kinesiophobia (TSK-11), which has a Cronbach’s alpha of 0.78 (Gómez-Pérez, López-Martínez, \& Ruiz-Párraga, 2011). The final score can range between 11 and 44 points, with higher scores indicating greater perceived fear of movement.

Physical disability due to LBP was assessed using the Spanish version of the Roland-Morris Disability Questionnaire (RMDQ), which presented an internal consistency (Cronbach's alpha) of 0.84 to 0.93 and test-retest reliability ranging between 0.72 and 0.91 (Kovacs et al., 2002; Roland

We conducted a pilot study to determine the effect size between non-care seekers with nonspecific CLBP and care seekers with nonspecific CLBP using a pain drawing. The pilot study included 15 patients from each group and obtained an effect size (Cohen's $d$ ) of 0.66 . The sample size was estimated with $\mathrm{G}^{*}$ Power 3.1.7 for Windows (G*Power from University of Dusseldorf, Germany) 
228 (Faul, Erdfelder, Lang, \& Buchner, 2007). We opted to use an independent t-test in order to detect

229 differences between both symptomatic groups for WP. Moreover, we used an alpha error level of

2300.05 , a statistical power of $80 \%$ (1-B error), and an effect size of 0.66 . A total sample size of 60

231 patients (30 non-care seekers with nonspecific CLBP and 30 care seekers with nonspecific CLBP)

232 was estimated to ensure reliability.

\section{Data Analysis}

234 The sociodemographic and clinical variables of the participants were analyzed. The data were

235 summarized using frequency counts, descriptive statistics, summary tables and figures.

236 The data analysis was performed using the Statistics Package for Social Science (SPSS 20.00, IBM

237 Inc., USA). The categorical variables are shown as frequency and percentage. The quantitative

238 results of the study are represented by descriptive statistics (CI, mean, and standard deviation). For

239 all variables, the z-score was assumed to follow a normal distribution based on the central limit

240 theorem, given the groups had more than 30 participants (Kwak \& Kim, 2017; Mouri, 2013; Nixon,

241 Wonderling, \& Grieve, 2010). Student's t-test was used for the nonspecific CLBP group

242 comparisons (months of pain, pain intensity, days of pain/month, days of medication/month,

243 PPSA, WP and RMDQ). Cohen's $d$ effect sizes were calculated for a post hoc analysis of the

244 outcome variables. According to Cohen's method, the magnitude of the effect was classified as

245 small (0.20-0.49), medium (0.50-0.79) or large $(0.80)$.

246 A one-way analysis of variance (ANOVA) was used to analyze numerical variables among the

247 asymptomatic participants, the care-seeking group and the non-care-seeking group

248 (sociodemographic variables, ROMFE, ROMLF, CRDL, CRDR, HAD_D, HAD_A and TSK-11).

249 Significant ANOVA findings were followed up using a post hoc test with Bonferroni correction.

250 We calculated the partial eta-squared $\left(\eta_{p}{ }^{2}\right)$ as a measurement of the effect size for each main 
251 effect and interaction in the ANOVAS. For this analysis, $0.010-0.059,0.060-0.139$, and $>0.14$

252 represented small, medium and large effects, respectively (J Cohen, 1988; J Cohen, 1973).

253 To ensure control of the false positive rate, an adjustment of the p-values using the Benjamini-

254 Hochberg method was used (false discovery rate [FDR]). The FDR correction ensures that in no

255 case, if working with $95 \%$ confidence, will there be more than $5 \%$ of variables in which a false

256 positive has occurred (Benjamini, Y; Hochberg, Y., 1995).

257 We examined the PPSA and WP associations with psychological, functional and somatosensory

258 measures, using Pearson's correlation coefficient. A Pearson correlation coefficient $>0.60,0.30$

2590.60 and $<0.30$ indicated high, medium and low correlations, respectively (Hinkle, Wiersma, \&

260 Jurs, 1990). The variables that showed the highest correlation with PPSA and WP were used to

261 perform the subsequent regression analysis.

262 A multiple linear regression analysis was performed to estimate the strength of the associations

263 between the PPSA and WP results. PPSA and WP variables were used as predictors. Considering

264 the variables more strongly correlated with PPSA and WP, we performed the linear regression 265 analysis. The strength of the association was examined using regression coefficients (B), $\mathrm{P}$ values 266 and adjusted $\mathrm{R}^{2}$. Standardized beta coefficients were reported for each predictor variable. We

267 included the final reduced models to allow a direct comparison between the predictor variable and

268 the criterion variable, which we studied. For the data analysis, we used a $95 \% \mathrm{CI}$ and a $P$ value of 269 less than 0.05.

\section{RESULTS}


271 A total of 90 participants completed the study (30 patients with nonspecific CLBP who sought

272 care, 30 patients with nonspecific CLBP who do not seek care and 30 asymptomatic controls).

273 Table 1 shows the sociodemographic characteristics of the study participants.

\section{Primary Variable}

275 Pain expansion

276 Statistically significant differences were observed in the pain drawing, with pain expansion greater

277 in care seekers (Figure 1 and Figure 2). Student's t-test (for independent samples) revealed 278 significant differences between the groups for PPSA $(\mathrm{t}=-2.50 ; \mathrm{q}=0.02 ; \mathrm{d}=0.64)$ and WP $(\mathrm{t}=-$

$2792.77 ; \mathrm{q}=0.02 ; \mathrm{d}=0.71)$. Table 2 shows the intergroup comparison. A bar graph was made based 280 on the search for help and the variables of the pain expansion. This graph shows that there was 281 little dispersion in the sample with respect to these variables (Figure 3 and Figure 4).

\section{Secondary Variables}

283 Regarding the secondary variables, the strongest results showed significant differences in pain intensity $(\mathrm{t}=-2.35 ; \mathrm{q}=0.03 ; \mathrm{d}=-0.60)$ and frequency of medication $(\mathrm{t}=-2.86 ; \mathrm{q}=0.003 ; \mathrm{d}=-$ 0.73) between care seekers and non-care seekers, with higher intensity in care seekers. Data with respect to physical, somatosensory and psychosocial variables are summarized in Tables 2 and 3.

\section{Correlation and Regression Analyses}

Pearson's correlation analysis showed only a moderate correlation, observed in the pain drawing, between functional and psychological variables in the care-seeking group of patients with nonspecific CLBP. The most significant correlations in this group were the association between 
291 right and left dynamic stability and the number of pain sites $(\mathrm{r}=-.540, \mathrm{P}<0.01 ; \mathrm{r}=-.564, \mathrm{P}<$

2920.01 , respectively), the association between depression and the number of pain sites $(\mathrm{r}=.436, \mathrm{P}<$ $2930.05)$ and the association of the same variable with PPSA $(r=.428, \mathrm{P}<0.05)$. Finally, a negative 294 correlation was also established between the ROMFE and the PPSA $(\mathrm{r}=-.391, \mathrm{P}<0.05)$ and 295 between the days of medication intake and the number of pain sites $(r=.393, P<0.05)$ (Table 4).

296 In contrast, in the group of patients with nonspecific CLBP who did not seek care, we found no 297 correlation between the main variable of the study and variables of a functional or psychological 298 nature (Table 4).

299 The regression models for the criteria variables (PPSA and WP) are presented in Table 5. The 300 regression model for the nonspecific CLBP care-seeking group showed that a combination of CRD 301 L (\%) and depression were predictors of PPSA (34.6\% of variance). The variables of CRD R (\%) 302 and days of medication per month were excluded from the analysis. Instead of the combination of 303 CRD L, ROMFE and depression were predictors of WP (48.5\% of variance). The variable of CRD $304 \mathrm{R}(\%)$ was excluded from the analysis. For the non-care seeking group with nonspecific CLBP, 305 the regression analysis was not performed because no significant correlation was found with the 306 main study variable.

\section{DISCUSSION}

\section{Pain expansion and Care Seeking}

The main differences between the patient groups analyzed in this study concerned pain expansion. Individuals who sought care had almost double the number of regions affected by pain than those who did not seek care. 
312 The body pain diagram is a tool that provides relevant information. Its use has also been considered

313 for assessing the psychological state of patients due to the greater the number of pain areas and the

314 greater impact that psychological factors exert on the clinical condition (Haefeli \& Elfering, 2006).

315 In our study, individuals with greater pain expansion sought care and presented significantly

316 greater anxiety and depression, with a medium effect size. These data agree with previous studies,

317 in which patients with chronic pain in several body regions at the same time had anxiety levels

318 that were considered pathological compared with patients having more localized pain. Moreover,

319 they had greater depression and feelings of distress (Abbott, Foster, Hamilton, Ravenwood, \& Tan, 320 2015; Muñoz-García, Lopez-Uralde-Villanueva, Beltrán-Alacreu, La Touche, \& Fernández-

321 Carnero, 2016). Evidence has shown that CWP not only correlates with psychological variables

322 but also correlates with somatosensory variables, such as the severity of symptoms or mechanical

323 hyperalgesia (Ferrer-Peña, Muñoz-García, Calvo-Lobo, \& Fernández-Carnero, 2018). Our results

324 showed that patients with greater pain expansion who were in search of help presented a greater

325 alteration in pain intensity and in medication intake per month. Pain expansion and the presence

326 of generalized allodynia include as an underlying neurophysiological mechanism a possible central

327 sensitization process (Lluch-Girbés et al., 2016). This process might explain why our patients

328 seeking help had greater pain expansion, and thus, greater pain intensity, longer symptom duration

329 and a greater involvement of psychological variables.

330 Along these lines, our results found that those patients with greater pain expansion who also sought

331 care presented a significantly greater restriction of movement compared with the other groups.

332 Other studies have shown that individuals with LBP had greater restriction of movement and 333 slower speed of execution compared with asymptomatic individuals (Laird, Gilbert, Kent, \& 334 Keating, 2014; Sadler, Spink, Ho, De Jonge, \& Chuter, 2017). This reduction in range of motion 
335

336

337

338

339

340

341

342

343

344

345

346

347

348

349

350

351

352

353

354

355

and speed of execution are correlated with variables of a psychological nature, such as fear of movement (Thomas, France, Lavender, \& Johnson, 2008). These results are in line with the results obtained by Landmark, which show that the presence of widespread pain implies an alteration in functionality (Landmark et al., 2013).

In terms of dynamic stability, our results demonstrated significant differences between both symptomatic groups with respect to the asymptomatic group. The evidence available thus far shows that dynamic balance is reduced in patients with LBP (Hooper et al., 2016). Moreover, there were no differences based on their search for care. A recent study on patients with chronic hip pain had also shown that the dynamic stability in this population was altered and correlated with cognitive and sensory variables (Ferrer-Peña, Moreno-López, Calvo-Lobo, \& López-de-UraldeVillanueva \& Fernández-Carnero, 2018).

\section{- Characteristics of patients seeking care}

It is important to define, taking into account the results obtained, which factors can influence the search for care in patients with CLBP. Numerous studies have determined that the rate of transition from non-CWP to CWP varies from 9\% to 25\% (Jones et al., 2011; Larsson, Björk, Börsbo, \& Gerdle, 2012; McBeth, Lacey, \& Wilkie, 2014; Viniol et al., 2015a). A recent study published in 2019 had determined that the rate of CWP development in a period of 1 year in the general population is $5 \%$ and that the factors that most contribute to this development are chronicity, severity of symptoms and the involvement of at least 2 of 5 total body regions in which the interpretation of the body chart is divided (Landmark, Romundstad, Butler, Kaasa, \& Borchgrevink, 2019). Thus, given our results indicate that there are statistically significant 
356 differences in pain expansion between seekers and nonseekers of care in terms of age, pain

357 intensity and disability, we find these patient characteristics relevant.

358 The most recent systematic review determined that due to the current methodological

359 heterogeneity, it is difficult to clearly determine which social factors might lead to the search for

360 health care. Even so, it is estimated that the prevalence rate of health system use by LBP in Europe

361 is lower than in other countries such as the United States (Beyera, Brien, \& Campbell, 2019). In

362 relation to the age differences, it is estimated that the prevalence of CLBP increases gradually from

363 the age of 30 , which could contribute to a greater demand for health care at a later age (Hoy,

364 Brooks, Blyth, \& Buchbinder, 2010). Research studies have found a positive association between

365 age and medical service use, which could justify the significant difference between groups that we

366 started with in this study (Jacob, Zeev, \& Epstein, 2003a; Ono et al., 2015; Szpalski, Nordin,

367 Skovron, Melot, \& Cukier., 1995). In contrast, other sociodemographic characteristics, such as

368 marital status, have not shown any significant association with the use of the health system (Ono

369 et al., 2015).

370 On the other hand, certain characteristics of the pain experience, such as pain intensity, are factors

371 related to the search for health care (Beyera et al., 2019). Given this agrees with the results

372 observed in this study, a number of sociodemographic and pain-related factors could contribute to

373 the search for health care.

374 Similarly, one study on patients with CLBP determined that impaired functionality and disability

375 are factors positively associated with care seeking (Ferreira et al., 2010). Therefore, taking into

376 account the studies on patients with temporomandibular dysfunction, care seeking could imply the

377 presence of passive coping strategies. These strategies have shown a correlation with greater pain 
378 intensity, less functionality and higher rates of disability (Alhowimel, Alotaibi, Radford, \&

379 Coulson, 2018; Du et al., 2017; Jackson, Wang, Wang, \& Fan, 2014; Knittle et al., 2011).

380

381

382

383

384

385

386

387

388

389

390

391

392

393

394

395

396

397

398

399

400

Psychological factors also have a great influence on patients with chronic pain; the most influential are fear of movement, anxiety and depression. The results of this study showed significant differences between all study groups; fear of movement was the most notable difference between individuals with CLBP seeking help and asymptomatic individuals, with a large effect size. In relation to our results, one study had shown that in patients with temporomandibular dysfunction, the decision to seek care was correlated with higher pain intensity and greater fear of movement (Rollman, A., Visscher, C.M., Gorter, R.C., \& Naeije, M.M, 2012). This outcome is in line with our results, given the patients with nonspecific CLBP who sought health care had higher fear of movement rates than those who did not seek help, with a large effect size.

These results could also be due to a statistically significant difference in the level of physical activity (PA) between groups, which can contribute to an alteration of the pain inhibitory system; however, it has also been observed that patients with chronic pain who perform PA can improve their symptomatology and physical function (Geneen et al., 2017). Even so, some studies have shown no direct relationship between PA levels and pain intensity; instead, the level of PA could be correlated with functionality (Griffin, Harmon, \& Kennedy, 2012; Hendrick et al., 2011). Along these lines, a recent study in patients with nonspecific CLBP who performed PA despite their pain found that, despite their pain, they showed no differences in range of motion and dynamic stability compared with asymptomatic individuals. Therefore, this could be a reason why those who seek help who also have a lower level of PA have statistically significant differences, with greater effect size, compared with asymptomatic individuals in those functional variables (Nieto-Garcia, SusoMarti, La Touche, \& Grande-Alonso, 2019). 
401

402 In contrast, the combination of psychological variables such as fear of movement and disability as

403 well as pain intensity, predicted dynamic stability in $43.8 \%$ of the individuals with chronic hip

404 pain (Ferrer-Peña et al., 2018). These data are important, given the relationship between CLBP

405 and hip pain, especially considering that in our study, dynamic stability together with depression

406 and/or ROMFE were variables predictive of pain expansion).

Finally, taking into account the prognostic factors in CLBP, the presence of depression and anxiety 408 influence the maintenance and recurrence of symptoms (Castro et al., 2011; Croft, Dunn, \& Raspe, 409 2006). A study by Hung et al. had found that depression was the most powerful psychological factor related to disability (Hung, Liu, \& Fu, 2015). On the other hand, there is little evidence on possible predictors of pain expansion. Our study shows that variables such as dynamic stability, in combination with depression and/or ROMFE, can predict pain expansion in $34.6 \%$ and $48.5 \%$ (PPSA and WP, respectively) of those who sought care. It is important to note that pain expansion is a powerful predictor of an alteration in the modulation of pain, in addition to the influence of variables such as anxiety, low expectation of recovery and hypersensitivity in various musculoskeletal pain conditions (Clark, Yeowell, Nijs, \& Goodwin, 2017; Smart, Blake, Staines, \& Doody, 2010). On the other hand, among the predictors of pain expansion in patients with CLBP

418 are the presence of psychosomatic symptoms, the female sex and a long duration of symptoms 419 (Viniol et al., 2015b).

\section{Study limitations}

421 This study has several limitations. First, the patients seeking help in this study presented a lower

422 level of PA compared with asymptomatic individuals and with patients with nonspecific CLBP 
423 who did not seek help. A systematic review had determined that the evidence is limited in terms

424 of improvement in pain severity as a result of exercise, instead determining that there is an

425 improvement in physical and psychological variables through this intervention (Geneen et al.,

426 2017). Another important limitation is age, given there were significant differences between

427 groups. However, research studies have shown that there is a positive correlation between age and

428 the search for health care (Jacob, Zeev, \& Epstein, 2003b; Ono et al., 2015; Szpalski et al., 1995).

429 Although previous research on pain expansion had also found statistically significant differences

430 in terms of the age variable, the difference was not considered clinically relevant (Muñoz-García

431 et al., 2016).

432 We recommend a more exhaustive evaluation based on somatosensory variables (pressure pain

433 thresholds, thermal thresholds and temporal summation) in the future to determine the presence of

434 a central sensitization process.

435 Another limitation is the selection of patients. Individuals with a medical diagnosis of fibromyalgia

436 were excluded. It is possible that there were some cases with similar characteristics to this

437 pathology, which should be taken into account. Schaefer et al. had concluded that future studies

438 are necessary, to determine the presence of fibromyalgia or CWP, given errors can be made in

439 sample selection due to the fact that these are different clinical conditions according to the

440 International Classification of Functioning, Disability and Health (Schaefer et al., 2016).

441 One of the main limitations of this study is the possibility of a type I error, which has been solved

442 by adjusting the p-values using the Benjamini-Hochberg method (false discovery rate).

443 Finally, the results of the present study should be interpreted with caution, given it is a cross-

444 sectional study; thus, causal relationships cannot be established. 


\section{CONCLUSIONS}

446 The results of this study show that patients who sought care presented greater WP than patients

447 who did not seek care. In addition, psychological and disability factors have a greater influence on

448 the experience of pain in patients with nonspecific CLBP who seek care, as well as their having a

449 reduced range of motion and less ability to discriminate two points. The CRD L, depression and

450 days of medication per month were covariates of PPSA (34.6\% of variance), and the composite

451 reach distance percentage of the left leg, depression and ROMFE were covariates of WP (48.5\%

452 of variance) for patients with nonspecific CLBP who sought care.

\section{Acknowledgments}

454 The authors thank the Miraflores Health Center (Alcobendas, Madrid, Spain) for their assistance 455 in collecting patients for the study.

\section{Conflicts of Interest}

457 The authors declare that they have no conflicts of interest.

458 This study did not receive any specific grant from funding agencies in the public, commercial or 459 not-for-profit sectors. 
461

462

463

464

465

466

467

468

469

470

471

472

473

474

475

476

477

478

479

480

481

482

483

484

485

486

487

488

489

490

491

492

493

494

495

496

497

498

499

500

\section{References}

Abbott, J. H., Foster, M., Hamilton, L., Ravenwood, M., \& Tan, N. (2015). Validity of pain drawings for predicting psychological status outcome in patients with recurrent or chronic low back pain. Journal of Manual \& Manipulative Therapy, 23(1), 12-19. https://doi.org/10.1179/2042618613Y.0000000046

Alhowimel, A., Alotaibi, M., Radford, K., \& Coulson, N. (2018). Psychosocial factors associated with change in pain and disability outcomes in chronic low back pain patients treated by physiotherapist: A systematic review. SAGE Open Medicine, 6, 1-8. https://doi.org/10.1177/2050312118757387

Bedekar, N., Suryawanshi, M., Rairikar, S., Sancheti, P., \& Shyam, A. (2014). Inter and intrarater reliability of mobile device goniometer in measuring lumbar flexion range of motion. $J$ Back Musculoskelet Rehabil, 27(2), 161-166. https://doi.org/10.3233/BMR-130431

Benjamini, Y; Hochberg, Y. (1995). Controlling the false discovery rate: a practical and powerful approach to multiple testing. J Roy Statist Soc Ser, 57 (1), 289-300.

Beyera, G. K., Brien, J. O., \& Campbell, S. (2019). Health-care utilisation for low back pain: a systematic review and meta-analysis of population-based observational studies. Rheumatology International, 39(10), 1663-1679. https://doi.org/10.1007/s00296-01904430-5

Bijur, P. E., Silver, W., \& Gallagher, E. J. (2001). Reliability of the visual analog scale for measurement of acute pain. Academic Emergency Medicine : Official Journal of the Society for Academic Emergency Medicine, 8(12), 1153-1157. https://doi.org/10.1111/j.15532712.2001.tb01132.x

Buchan, H. A., Duggan, A., Hargreaves, J., Scott, I. A., \& Slawomirski, L. (2016). Health care variation : time to act. Med J Aust, 205(10), 30-33. https://doi.org/10.5694/mja15.01360

Carmona, L., Ballina, J., Gabriel, R., \& Laffon, A. (2001). The burden of musculoskeletal diseases in the general population of Spain: Results from a national survey. Annals of the Rheumatic Diseases, 60(11), 1040-1045. https://doi.org/10.1136/ard.60.11.1040

Castro, M. M. C., Quarantini, L. C., Daltro, C., Pires-Caldas, M., Koenen, K. C., Kraychete, D. C., \& Oliveira, I. R. de. (2011). Comorbid depression and anxiety symptoms in chronic pain patients and their impact on health-related quality of life. Rev Psiq Clín., 38(4), 126-129. https://doi.org/10.1590/S0101-60832011000400002

Cimmino, M. A., Ferrone, C., \& Cutolo, M. (2011). Epidemiology of chronic musculoskeletal pain. Best Practice and Research: Clinical Rheumatology, 25(2), 173-183. https://doi.org/10.1016/j.berh.2010.01.012

Clark, J., Yeowell, G., Nijs, J., \& Goodwin, P. (2017). What are the predictive factors for central sensitisation in chronic musculoskeletal pain populations? A systematic review. Pain Physician, 20(6), 487-500. Retrieved from http://www.painphysicianjournal.com/current/pdf?article=NDYwMw\%3D\%3D\%0Ahttp:// www.ioe.ac.uk/ISWebsiteDocs/Guides/Library/SearchStrategyweb.pdf\%0Ahttp://www.ncb i.nlm.nih.gov/pubmed/28934779 
501

502

503

504

505

506

507

508

509

510

511

512

513

514

515

516

517

518

519

520

521

522

523

524

525

526

527

528

529

530

531

532

533

534

535

536

537

538

539

540

541

Cohen, J. (1973). Eta-squared and partial eta-squared in fixed factor anova designs. Educational and Psychological Measurement., 33(1), 107-112. https://doi.org/10.1177/001316447303300111

Cohen, J. (1988). Statistical power analysis for the behavioral sciences. (Lawrence Erlbaum Associates Inc., Ed.). Hillsdale.

Craig, C., Marshall, A., Sjöström, M., Bauman, A., Booth, M., Ainsworth, B., ... Oja, P. (2003). International Physical Activity Questionnaire : 12-Country Reliability and Validity. Med Sci Sports Exerc., 35(8), 1381-1395. https://doi.org/10.1249/01.MSS.0000078924.61453.FB

Croft, P. R., Dunn, K. M., \& Raspe, H. (2006). Course and prognosis of back pain in primary care: The epidemiological perspective. Pain, 122(1-2), 1-3. https://doi.org/10.1016/j.pain.2006.01.023

De Las Cuevas-Castresana, C., García-Estrada Pérez, A., \& Gónzalez de Rivera, J. (1995). "Hospital Anxiety and Depression Scale" y psicopatología afectiva. An Psiquiatr., 11(4), 126-130. Retrieved from http://www.ncbi.nlm.nih.gov/pubmed/3461421

Dos Reis, F. J., de Barros E Silva, V., de Lucena, R. N., Mendes Cardoso, B. A., \& Nogueira, L. C. (2016). Measuring the Pain Area: An Intra- and Inter-Rater Reliability Study Using Image Analysis Software. Pain Practice: The Official Journal of World Institute of Pain, 16(1), 24-30. https://doi.org/10.1111/papr.12262

Dragioti, E., Larsson, B., Bernfort, L., Levin, L. Å., \& Gerdle, B. (2017). A cross-sectional study of factors associated with the number of anatomical pain sites in an actual elderly general population: Results from the pains65+ cohort. Journal of Pain Research, 10(23), 20092019. https://doi.org/10.2147/JPR.S143060

Du, S., Hu, L., Bai, Y., Dong, J., Jin, S., Zhang, H., \& Zhu, Y. (2017). The influence of selfefficacy, fear-avoidance belief, and coping styles on quality of life for Chinese patients with chronic non-specific low back pain: A multi-site cross-sectional study. Pain Practice, 23(11), 1-12. https://doi.org/10.1111/papr.12660.

Faul, F., Erdfelder, E., Lang, A.-G., \& Buchner, A. (2007). G*Power 3: a flexible statistical power analysis program for the social, behavioral, and biomedical sciences. Behavior Research Methods, 39(2), 175-191. Retrieved from http://www.ncbi.nlm.nih.gov/pubmed/17695343

Ferreira, M. L., Machado, G., Latimer, J., Maher, C., Ferreira, P. H., \& Smeets, R. J. (2010). Factors defining care-seeking in low back pain - A meta-analysis of population based surveys. European Journal of Pain, 14(7), 747.e1-747.e7. https://doi.org/10.1016/j.ejpain.2009.11.005

Ferrer-Peña, R., Moreno-López, M., Calvo-Lobo, C., \& López-de-Uralde-Villanueva, I Fernández-Carnero, J. (2018). Relationship of Dynamic Balance Impairment with PainRelated and Psychosocial Measures in Primary Care Patients with Chronic Greater Trochanteric Pain Syndrome. Pain Med, 22(8), 1-8. https://doi.org/10.1093/pm/pny160

Ferrer-Peña, R., Muñoz-García, D., Calvo-Lobo, C., \& Fernández-Carnero, J. (2018). Pain Expansion and Severity Reflect Central Sensitization in Primary Care Patients with Greater Trochanteric Pain Syndrome. Pain Medicine, 0(0), 1-10. 
542

543

544

545

546

547

548

549

550

551

552

553

554

555

556

557

558

559

560

561

562

563

564

565

566

567

568

569

570

571

572

573

574

575

576

577

578

579

580

581

582

https://doi.org/10.1093/pm/pny199

Geneen, L. J., More, R. A., Clarke, C., Martin, D., Colvin, L. A., \& Smith, B. H. (2017).

Physical activity and exercise for chronic pain in adults: an overview of Cochrane Reviews (Review). Journal of Sociology, (4), 135-139.

https://doi.org/10.1002/14651858.CD011279.pub3.www.cochranelibrary.com

Gómez-Pérez, L., López-Martínez, A. E., \& Ruiz-Párraga, G. T. (2011). Psychometric Properties of the Spanish Version of the Tampa Scale for Kinesiophobia (TSK). The Journal of Pain : Official Journal of the American Pain Society, 12(4), 425-435. https://doi.org/10.1016/j.jpain.2010.08.004

Goubert, D., Danneels, L., \& Graven-nielsen, T. (2017). Differences in Pain Processing Between Patients with Chronic Low Back Pain, Recurrent Low Back Pain, and Fibromyalgia. Pain Physician, 20(4), 307-318.

Grande-Alonso, M., Suso-Martí, L., Cuenca-Martínez, F., Pardo-Montero, J., Gil-Martínez, A., \& La Touche, R. (2019). Physiotherapy Based on a Biobehavioral Approach with or Without Orthopedic Manual Physical Therapy in the Treatment of Nonspecific Chronic Low Back Pain: A Randomized Controlled Trial. Pain Medicine, 0(0), 1-17. https://doi.org/10.1093/pm/pnz093

Griffin, D. W., Harmon, D. C., \& Kennedy, N. M. (2012). Do patients with chronic low back pain have an altered level and / or pattern of physical activity compared to healthy individuals? A systematic review of the literature. Physiotherapy, 98(1), 13-23. https://doi.org/10.1016/j.physio.2011.04.350

Haefeli, M., \& Elfering, A. (2006). Pain assessment. European Spine Journal : Official Publication of the European Spine Society, the European Spinal Deformity Society, and the European Section of the Cervical Spine Research Society, 15 Suppl 1, S17-24. https://doi.org/10.1007/s00586-005-1044-X

Hagen, K., Linde, M., Heuch, I., Stovner, L. J., \& Zwart, J.-A. (2011). Increasing Prevalence of Chronic Musculoskeletal Complaints. A Large 11-Year Follow-Up in the General Population (HUNT 2 and 3). Pain Medicine, 12(11), 1657-1666. https://doi.org/10.1111/j.1526-4637.2011.01240.x

Hägg, O., Fritzell, P., Hedlund, R., Möller, H., Ekselius, L., \& Nordwall, A. (2003). Paindrawing does not predict the outcome of fusion surgery for chronic low-back pain: a report from the Swedish Lumbar Spine Study. European Spine Journal, 12, 2-11. https://doi.org/10.1007/s00586-002-0427-5

Hashmi, J. A., Baliki, M. N., Huang, L., Baria, A. T., Torbey, S., Hermann, K. M., ... Apkarian, A. V. (2013). Shape shifting pain: Chronification of back pain shifts brain representation from nociceptive to emotional circuits. Brain, 136(9), 2751-2768. https://doi.org/10.1093/brain/awt211

Hendrick, P., \& Hale, S. M. L. (2011). The relationship between physical activity and low back pain outcomes : a systematic review of observational studies. Eur. Spine J., 20, 464-474. https://doi.org/10.1007/s00586-010-1616-2

Herrmann, C. (1997). International experiences with the hospital anxiety and depression scale - 
583 584

585 586

587

588

589

590

591

592

593

594

595

596

597

598

599

600

601

602

603

604

605

606

607

608

609

610

611

612

613

614

615

616

617

618

619

620

621

622

A review of validation data and clinical results. Journal of Psychosomatic Research, 42(1), 17-41. https://doi.org/10.1016/S0022-3999(96)00216-4

Hinkle, D. E., Wiersma, W., \& Jurs, S. G. (1990). Applied Statistics for the Behavioral Sciences. Source: Journal of Educational Statistics, 15(1), 84-87.

Hooper, T. L., James, C. R., Brismée, J. M., Rogers, T. J., Gilbert, K. K., Browne, K. L., \& Sizer, P. S. (2016). Dynamic balance as measured by the Y-Balance Test is reduced in individuals with low back pain: A cross-sectional comparative study. Physical Therapy in Sport, 22, 29-34. https://doi.org/10.1016/j.ptsp.2016.04.006

Hoy, D., Brooks, P., Blyth, F., \& Buchbinder, R. (2010). The Epidemiology of low back pain. Best Practice and Research: Clinical Rheumatology, 24(6), 769-781. https://doi.org/10.1016/j.berh.2010.10.002

Hung, C.-I., Liu, C.-Y., \& Fu, T.-S. (2015). Depression: An important factor associated with disability among patients with chronic low back pain. The International Journal of Psychiatry in Medicine, 49(3), 187-198. https://doi.org/10.1177/0091217415573937

IASP. (2017). International Association for the Study of Pain (IASP) https://www.iasp-pain.org/ Education/Content.aspx?ItemNumber $=1698 \#$ Nociplasticpain. Retrieved from https://www.iasp-pain.org/Education/Content.aspx?ItemNumber=1698\#Nociplasticpain

IJzelenberg, W., \& Burdorf, A. (2004). Impact of musculoskeletal co-morbidity of neck and upper extremities on healthcare utilisation and sickness absence for low back pain. $O C C U$, 61(10), 806-810. https://doi.org/10.1136/oem.2003.011635

Jackson, T., Wang, Y., Wang, Y., \& Fan, H. (2014). Self-efficacy and chronic pain outcomes: A meta-analytic review. Journal of Pain, 15(8), 800-814.

https://doi.org/10.1016/j.jpain.2014.05.002

Jacob, T., Zeev, A., \& Epstein, L. (2003a). Low back pain- a community based study of careseeking and therapeutic effectiveness. Disability and Rehabilitation, 25(2), 67-76. https://doi.org/10.1080/0963828021000007905

Jacob, T., Zeev, A., \& Epstein, L. (2003b). Low back pain - a communitybased study of careseeking and therapeutic effectiveness. Disability and Rehabilitation, 25(2), 67-76.

Jones, G. T., Nicholl, B. I., McBeth, J., Davies, K. A., Morriss, R. K., Dickens, C., \& MacFarlane, G. J. (2011). Role of road traffic accidents and other traumatic events in the onset of chronic widespread pain: Results from a population-based prospective study. Arthritis Care and Research, 63(5), 696-701. https://doi.org/10.1002/acr.20417

Knittle, K. P., De Gucht, V., Hurkmans, E. J., Vlieland, T. P., Peeters, A. J., Ronday, H. K., \& Maes, S. (2011). Effect of self-efficacy and physical activity goal achievement on arthritis pain and quality of life in patients with rheumatoid arthritis. Arthritis Care \& Research, 63(11), 1613-1619. https://doi.org/10.1002/acr.20587

Kolber, M. J., Mdt, C., Pizzini, M., Robinson, A., Yanez, D., \& Hanney, W. J. (2013). Original research the reliability and concurrent validity of measurements used to quantify lumbar spine mobility: an analysis of an iphone application. The International Journal of Sports Physical Therapy, 8(2), 129-137.

Peer] reviewing PDF | (2019:08:40707:2:0:CHECK 5 Feb 2020) 
623

624

625

626

627

628

629

630

631

632

633

634

635

636

637

638

639

640

641

642

643

644

645

646

647

648

649

650

651

652

653

654

655

656

657

658

659

660

661

662

Kovacs, F. M., Llobera, J., Gil Del Real, M. T., Abraira, V., Gestoso, M., Fernández, C., \& Primaria Group, K.-A. (2002). Validation of the spanish version of the Roland-Morris questionnaire. Spine, 27(5), 538-542.

Kwak, S. G., \& Kim, J. H. (2017). Central limit theorem: The cornerstone of modern statistics. Korean Journal of Anesthesiology, 70(2), 144-156. https://doi.org/10.4097/kjae.2017.70.2.144

Laird, R. A., Gilbert, J., Kent, P., \& Keating, J. L. (2014). Comparing lumbo-pelvic kinematics in people with and without back pain : a systematic review and meta-analysis. $B M C$ Musculoskeletal Disorders, 10(15), 1-13. https://doi.org/10.1186/1471-2474-15-229

Landmark, T., Romundstad, P., Butler, S., Kaasa, S., \& Borchgrevink, P. (2019). Development and course of chronic widespread pain. Pain, 160(9), 1976-1981. https://doi.org/10.1097/j.pain.0000000000001585

Landmark, T., Romundstad, P., Dale, O., Borchgrevink, P. C., Vatten, L., \& Kaasa, S. (2013). Chronic pain: One year prevalence and associated characteristics (the HUNT pain study). Scandinavian Journal of Pain, 4(4), 182-187. https://doi.org/10.1016/j.sjpain.2013.07.022

Larsson, B., Björk, J., Börsbo, B., \& Gerdle, B. (2012). A systematic review of risk factors associated with transitioning from regional musculoskeletal pain to chronic widespread pain. European Journal of Pain (United Kingdom), 16(8), 1084-1093. https://doi.org/10.1002/j.1532-2149.2012.00117.x

Lluch-Girbés, E., Dueñas, L., Barbero, M., Falla, D., Baert, I. A. C., Meeus, M., ... Nijs, J. (2016). Expanded Distribution of Pain as a Sign of Central Sensitization in Individuals With Symptomatic Knee Osteoarthritis. Phys Ther, 96(8), 1196-1207.

Macfarlane, TV; Blinkhorn, AS; Davies, RM; Kincey, J; Worthington, H. (2003). Factors associated with health care seeking behaviour for orofacial pain in the general population. Community Dent Health, 20(1), 20-26.

Mannion, A. R., Wieser, S., \& Elfering, A. (2013). Association Between Beliefs and CareSeeking Behavior for Low Back Pain. Spine, 38(12), 1016-1025. https://doi.org/10.1097/BRS.0b013e31828473b5

McBeth, J., Lacey, R. J., \& Wilkie, R. (2014). Predictors of new-onset widespread pain in older adults. Arthritis and Rheumatology, 66(3), 757-767. https://doi.org/10.1002/art.38284

Merskey, H; Bogduk, N. (1994). Classification of Chronic Pain: Descriptions of Chronic Pain Syndromes and Definitions of Pain Terms. Seattle: IASP Press.

Mouri, H. (2013). Log-normal distribution from a process that is not multiplicative but is additive. Physical Review E, 88, 042124. https://doi.org/10.1103/PhysRevE.88.042124

Muñoz-García, D., Lopez-Uralde-Villanueva, I., Beltrán-Alacreu, H., La Touche, R., \& Fernández-Carnero, J. (2016). Patients with Concomitant Chronic Neck Pain and Myofascial Pain in Masticatory Muscles Have More Widespread Pain and Distal Hyperalgesia than Patients with Only Chronic Neck Pain. Pain Medicine, pnw274. https://doi.org/10.1093/pm/pnw274

Nieto-Garcia, J., Suso-Marti, L., La Touche, R., \& Grande-Alonso, M. (2019). Somatosensory

PeerJ reviewing PDF | (2019:08:40707:2:0:CHECK 5 Feb 2020) 
663

664

665

666

667

668

669

670

671

672

673

674

675

676

677

678

679

680

681

682

683

684

685

686

687

688

689

690

691

692

693

694

695

696

697

698

699

700

701

702

and Motor Di ff erences between Physically Active Patients with Chronic Low Back Pain and Asymptomatic Individuals. Medicina, 55(9), 1-13.

Nixon, R. M., Wonderling, D., \& Grieve, R. D. (2010). Non-parametric methods for costeffectiveness analysis: the central limit theorem and the bootstrap compared. Health Economics, 19(3), 316-333. https://doi.org/10.1002/hec.1477

Ono, R., Yamazaki, S., Takegami, M., Suzukamo, Y., Konno, S., Kikuchi, S., \& Fukuhara, S. (2015). Patient-reported disability in the general Japanese population was associated with medical care visits for low back pain, regardless of pain intensity. Journal of Orthopaedic Science, 20(4), 742-749. https://doi.org/10.1007/s00776-015-0719-3

Papageorgiou, A. C., Silman, A. J., \& Macfarlane, G. J. (2002). Chronic widespread pain in the population: A seven year follow up study. Annals of the Rheumatic Diseases, 61(12), 10711074. https://doi.org/10.1136/ard.61.12.1071

Persson, A. L., Garametsos, S., \& Pedersen, J. (2011). Computer-aided surface estimation of pain drawings - intra- and inter-rater reliability. Journal of Pain Research, 4, 135-141. https://doi.org/10.2147/JPR.S18637

Plisky, P. J., Gorman, P. P., Butler, R. J., Kiesel, K. B., Underwood, F. B., \& Elkins, B. (2009). The reliability of an instrumented device for measuring components of the Star Excursion Balance Test. North American Journal of Sports Physical Therapy, 4(May 2009), 92. https://doi.org/10.2519/jospt.2006.2244

Reis, F., Guimarães, F., Nogueira, L. C., Meziat-Filho, N., Sanchez, T. A., \& Wideman, T. (2018). Association between pain drawing and psychological factors in musculoskeletal chronic pain: A systematic review. Physiotherapy Theory and Practice, 00(00), 1-10. https://doi.org/10.1080/09593985.2018.1455122

Ris, I., Barbero, M., Falla, D., Larsen, M., Nielsen, M., Søgaard, K., \& Juul-kristensen, B. (2019). Pain extent is more strongly associated with disability, psychological factors, and neck muscle function in people with non-traumatic versus traumatic chronic neck pain: a cross sectional study. Eur J Phys Rehabil Med, 55(1), 71-78. https://doi.org/10.23736/S1973-9087.18.04977-8

Roland, M., \& Fairbank, J. (2000). The Roland-Morris disability questionnaire and the Oswestry disability questionnaire. Spine, 25(24), 3115-3124. https://doi.org/10.1097/00007632200012150-00006

Rollman, A., Visscher, C. M., Gorter, R. C., \& Naeije, M. (2012). Care seeking for orofacial pain. J Orofac Pain, 26(3), 206-214.

Rollman, A., Gorter, R. C., Visscher, C. M., \& Naeije, M. M. (2013). Why seek treatment for temporomandibular disorder pain complaints? A study based on semi-structured interviews. Journal of Orofacial Pain, 27(3), 227-234. https://doi.org/10.11607/jop.1081

Sadler, S. G., Spink, M. J., Ho, A., De Jonge, X. J., \& Chuter, V. H. (2017). Restriction in lateral bending range of motion, lumbar lordosis, and hamstring flexibility predicts the development of low back pain: A systematic review of prospective cohort studies. $B M C$ Musculoskeletal Disorders, 18(1), 1-15. https://doi.org/10.1186/s12891-017-1534-0 
703

704

705

706

707

708

709

710

711

712

713

714

715

716

717

718

719

720

721

722

723

724

725

726

727

728

729

730

731

732

733

734

735

736

737

738

739

740

741

742

Savigny, P., Watson, P., \& Underwood, M. (2009). Early management of persistent non-specific low back pain: summary of NICE guidance. BMJ (Clinical Research Ed.), 338(June), 14411445. https://doi.org/10.1136/bmj.b1805

Schaefer, C., Mann, R., Masters, E. T., Cappelleri, J. C., Daniel, S. R., Zlateva, G., ... Staud, R. (2016). The Comparative Burden of Chronic Widespread Pain and Fibromyalgia in the United States. Pain Practice, 16(5), 565-579. https://doi.org/10.1111/papr.12302

Shaffer, S. W., Teyhen, D. S., Lorenson, C. L., Warren, R. L., Koreerat, C. M., Straseske, C. A., \& Childs, J. D. (2013). Y-Balance Test: A Reliability Study Involving Multiple Raters. Military Medicine, 178(11), 1264-1270. https://doi.org/10.7205/MILMED-D-13-00222

Smart, K. M., Blake, C., Staines, A., \& Doody, C. (2010). Clinical indicators of "nociceptive", "peripheral neuropathic" and "central" mechanisms of musculoskeletal pain. A Delphi survey of expert clinicians. Manual Therapy, 15(1), 80-87. https://doi.org/10.1016/j.math.2009.07.005

Szpalski, M., Nordin, M., Skovron, M., Melot, C., \& Cukier., D. (1995). Health care utilization for low back pain in Belgium. Influence of sociocultural factors and health beliefs. Spine, 20(4), 431-442.

Teyhen, D., Shaffer, S., Lorenson, C., Greenberg, M., Rogers, S., Koreerat, C., ... Childs, J. (2014). Clinical measures associated with dynamic balance and functional movement. $J$ Strength Cond Res, 28(5), 1272-1283.

Thomas, J. S., France, C. R., Lavender, S. A., \& Johnson, M. R. (2008). Effects of fear of movement on spine velocity and acceleration after recovery from low back pain. Spine, 33(5), 564-570. https://doi.org/10.1097/BRS.0b013e3181657f1a

Tong, M. H., Mousavi, S. J., Kiers, H., Ferreira, P., Refshauge, K., \& van Dieën, J. (2017). Is There a Relationship Between Lumbar Proprioception and Low Back Pain? A Systematic Review With Meta-Analysis. Archives of Physical Medicine and Rehabilitation, 98(1), 120-136.e2. https://doi.org/10.1016/j.apmr.2016.05.016

Traeger, A. C., Buchbinder, R., Elshaug, A. G., Croft, R., \& Maher, C. G. (2019). Care for low back pain : can health systems deliver? Bull World Health Organ, 30(April), 423-433.

Viniol, A., Jegan, N., Brugger, M., Leonhardt, C., Barth, J., Baum, E., ... Strauch, K. (2015a). Even worse - Risk factors and protective factors for transition from chronic localized low back pain to chronic widespread pain in general practice. Spine, 40(15), E890-E899. https://doi.org/10.1097/BRS.0000000000000980

Viniol, A., Jegan, N., Brugger, M., Leonhardt, C., Barth, J., Baum, E., ... Strauch, K. (2015b). Even worse - Risk factors and protective factors for transition from chronic localized low back pain to chronic widespread pain in general practice. Spine, 40(15), E890-E899. https://doi.org/10.1097/BRS.0000000000000980

von Elm, E., Altman, D. G., Egger, M., Pocock, S. J., Gøtzsche, P. C., Vandenbroucke, J. P., \& STROBE Initiative. (2008). The Strengthening the Reporting of Observational Studies in Epidemiology (STROBE) statement: guidelines for reporting observational studies. Journal of Clinical Epidemiology, 61(4), 344-349. https://doi.org/10.1016/j.jclinepi.2007.11.008 
743 Walsh, N. E., Brooks, P., Hazes, J. M., Walsh, R. M., Dreinhöfer, K., Woolf, A. D., ... Lidgren, L. (2008). Standards of Care for Acute and Chronic Musculoskeletal Pain: The Bone and Joint Decade (2000-2010). Archives of Physical Medicine and Rehabilitation, 89(9), 18301845. https://doi.org/10.1016/j.apmr.2008.04.009

Wolfe, F., Smythe, H. A., Yunus, M. B., Bennett, R. M., Bombardier, C., Goldenberg, D. L., ... Clark, P. (1990). The American College of Rheumatology 1990 Criteria for the Classification of Fibromyalgia. Report of the Multicenter Criteria Committee. Arthritis and Rheumatism, 33(2), 160-172. Retrieved from 


\section{FIGURES}

755 FIGURE 1. Pain expansion in patients who sought care. 
756 FIGURE 2. Pain expansion in patients who did not seek care.

757

758

759

760

761

762

763

764

765

766

767

768

769

770

771

772

773

774

775

776

777

778

779

780

Peer] reviewing PDF | (2019:08:40707:2:0:CHECK 5 Feb 2020) 
FIGURE 3. Scatter plot for PPSA.

784

785

786

787

788

789

790

791

792

793

794

795

796

797

798

799

800

801

802

803

804

805

Peer] reviewing PDF | (2019:08:40707:2:0:CHECK 5 Feb 2020) 
810 FIGURE 4. Scatter plot for WP. 


\section{Table $\mathbf{1}$ (on next page)}

Descriptive statistics of socio-demographic data.

Values are presented as mean \pm standard deviation or number (\%). BMI: Body Mass Index

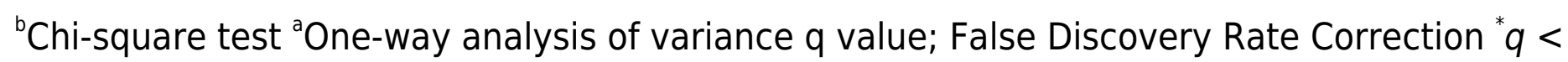
$.05 ;{ }^{* *} q<.01$. 
1 Table 1. Descriptive statistics of socio-demographic data.

2

3

\begin{tabular}{|c|c|c|c|c|}
\hline Measures & $\begin{array}{l}\text { Asymptomatic } \\
\qquad(\mathrm{n}=\mathbf{3 0})\end{array}$ & $\begin{array}{l}\text { Non care seekers } \\
\qquad(\mathbf{n}=\mathbf{3 0})\end{array}$ & $\begin{array}{l}\text { Care Seekers } \\
\qquad(\mathbf{n}=\mathbf{3 0})\end{array}$ & $\begin{array}{c}\text { FDR-Adjusted } \\
\text { p-values } \\
\text { a.k.a q value }\end{array}$ \\
\hline Age $^{a}$ & $38.30 \pm 13.09$ & $37.93 \pm 12.30$ & $46.07 \pm 10.90$ & $.02^{* *}$ \\
\hline Gender $^{b}$ & & & & .87 \\
\hline Male (\%) & $13(43.3)$ & $14(46.7)$ & $12(40)$ & \\
\hline Female (\%) & $17(56.7)$ & $16(53.3)$ & $18(60)$ & \\
\hline Height (cm) & $167.47 \pm 9.76$ & $171 \pm 8.42$ & $166.73 \pm 10.14$ & .23 \\
\hline Weight (kg) ${ }^{\mathrm{a}}$ & $69.20 \pm 16.87$ & $72.22 \pm 11.95$ & $73.54 \pm 17.50$ & .60 \\
\hline BMI $\left(\mathrm{Kg} / \mathbf{m}^{2}\right)$ & $24.48 \pm .83$ & $24.61 \pm .55$ & $26.4 \pm 1.05$ & .23 \\
\hline $\begin{array}{c}\text { Educational } \\
\text { Level }^{\mathbf{b}}\end{array}$ & & & & .09 \\
\hline Primary & $4(13.3)$ & $3(10)$ & $10(33.3)$ & \\
\hline Education (\%) & & & & \\
\hline $\begin{array}{c}\text { Secondary } \\
\text { education (\%) }\end{array}$ & $4(13.3)$ & $2(6.6)$ & $5(16.7)$ & \\
\hline $\begin{array}{c}\text { College } \\
\text { education (\%) }\end{array}$ & $22(73.3)$ & $25(83.3)$ & $15(50)$ & \\
\hline $\begin{array}{c}\text { Level of physical } \\
\text { activity }^{b}\end{array}$ & & & & $.03^{* *}$ \\
\hline Mild (\%) & $5(16.7)$ & $4(13.3)$ & $11(36.7)$ & \\
\hline Moderate (\%) & $8(26.7)$ & $15(50)$ & $12(40)$ & \\
\hline Vigorous (\%) & $17(56.7)$ & $11(36.7)$ & $7(23.3)$ & \\
\hline Medication $^{b}$ & & & & $.003^{* *}$ \\
\hline None & $30(100.0)$ & $19(63.3)$ & $7(23.3)$ & \\
\hline
\end{tabular}




$\begin{array}{cccc}\text { Ibuprofen } & 0(0.0) & 10(33.3) & 20(66.7) \\ \text { Paracetamol } & 0(0.0) & 1(3.3) & 3(10.0)\end{array}$

4

5 Values are presented as mean \pm standard deviation or number (\%). BMI: Body Mass Index

$6{ }^{\mathrm{b}}$ Chi-square test

7 ane-way analysis of variance

8 q value; False Discovery Rate Correction

$9 \quad{ }^{*} q<.05 ;{ }^{* *} q<.01$.

10 


\section{Table 2 (on next page)}

Descriptive and multiple comparisons of somatosensory and motor variables.

Values are presented as mean \pm standard deviation. VAS: Visual Analogue Scale; PPSA:

Percentage Pain Surface Area; WP: Widespread Pain; ROMFE: Range of movement in Flexoextension; ROMLF: Range of movement in lateral flexion; CRD L (\%): Composite Reach Distance Left (\%); CRD R (\%): Composite Reach Distance Right (\%). ${ }^{a}$ One-way analysis of variance IIndependent Student's t test. q value; False Discovery Rate Correction ${ }^{*} q<.05 ;{ }^{* *} q$ $<.01$. 
1 Table 2. Descriptive and multiple comparisons of somatosensory and motor variables.

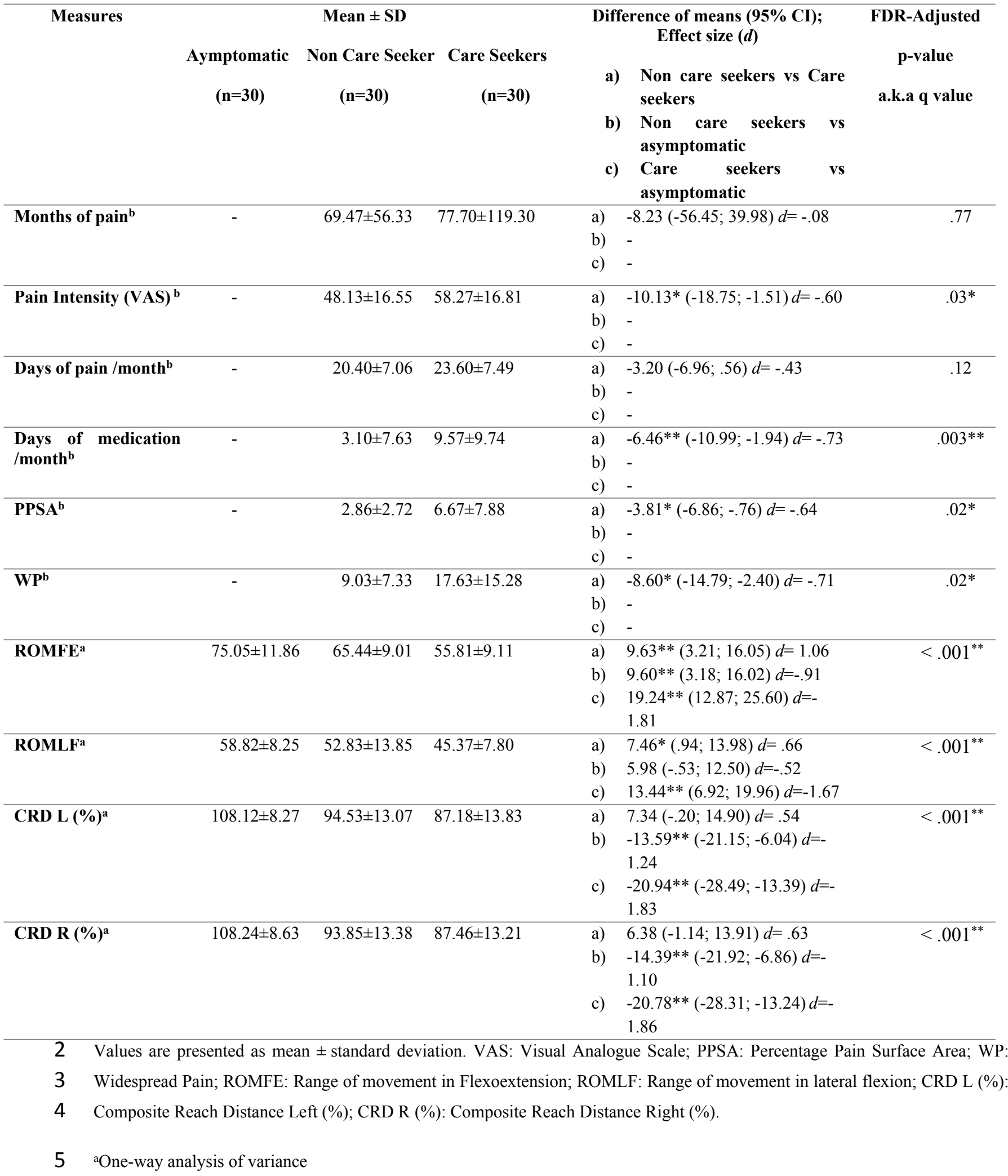


6 'Independent Student's t test.

7 q value; False Discovery Rate Correction

$8 \quad{ }^{*} q<.05 ;{ }^{* *} q<.01$.

9 


\section{Table 3 (on next page)}

Descriptive and multiple comparisons of psychological variables.

Values are presented as mean \pm standard deviation. RMDQ: Roland-Morris Disability

Questionnaire; HAD_A: Anxiety; HAD_D: Depression; TSK-11: Tampa Scale of Kinesiophobia. ${ }^{a}$

One-way analysis of variance ${ }^{b}$ Independent Student's t test. q value; False Discovery Rate

Correction ${ }^{*} q<.05 ;{ }^{* *} q<.01$. 
1 Table 3. Descriptive and multiple comparisons of psychological variables.

\begin{tabular}{|c|c|c|c|c|c|c|}
\hline \multirow{4}{*}{ Measures } & \multirow{4}{*}{$\begin{array}{l}\text { Aymptomatic } \\
\qquad(\mathrm{n}=\mathbf{3 0})\end{array}$} & \multirow{4}{*}{$\begin{array}{c}\text { Mean } \pm \text { SD } \\
\text { Non Care Seekers }\end{array}$} & \multirow{4}{*}{$\begin{array}{l}\text { Care Seekers } \\
(\mathbf{n}=\mathbf{3 0})\end{array}$} & \multicolumn{2}{|c|}{$\begin{array}{c}\text { Difference of means }(95 \% \mathrm{CI}) \text {; Effect } \\
\text { size }(d)\end{array}$} & \multirow{4}{*}{$\begin{array}{l}\text { FDR-Adjusted } \\
\text { p-value } \\
\text { a.k.a q-value }\end{array}$} \\
\hline & & & & \multirow{3}{*}{$\begin{array}{l}\text { a) } \\
\text { b) }\end{array}$} & $\begin{array}{l}\text { Non care seekers vs Care } \\
\text { seekers }\end{array}$ & \\
\hline & & & & & $\begin{array}{l}\text { Non care seekers vs } \\
\text { asymptomatic }\end{array}$ & \\
\hline & & & & & Care seekers vs asymptomatic & \\
\hline \multirow[t]{3}{*}{$\mathbf{R M D Q}^{\mathrm{b}}$} & - & $3.97 \pm 2.32$ & $7.73 \pm 4.44$ & a) & $-3.76^{* *}(-5.60 ;-1.93) d=-1.06$ & $.003^{* *}$ \\
\hline & & & & b) & - & \\
\hline & & & & c) & - & \\
\hline \multirow[t]{3}{*}{ HAD_A $\mathbf{A}^{\mathrm{a}}$} & $5.10 \pm 3.52$ & $5.43 \pm 3.51$ & $8.10 \pm 4.52$ & a) & $2.66^{*}(.22 ; 5.12) d=-.65$ & $.02^{*}$ \\
\hline & & & & b) & $.33(-2.12 ; 2.78) d=.09$ & \\
\hline & & & & c) & $3.00^{* *}(.55 ; 5.45) d=.74$ & \\
\hline \multirow[t]{3}{*}{ HAD_Da } & $1.67 \pm 2.35$ & $2.37 \pm 2.41$ & $4.77 \pm 4.01$ & a) & $2.40^{* *}(.49 ; 4.31) d=-.72$ & $<.001^{* *}$ \\
\hline & & & & b) & $.70(-1.21 ; 2.61) d=.29$ & \\
\hline & & & & c) & $3.10^{* *}(1.19 ; 5.01) d=.94$ & \\
\hline \multirow[t]{3}{*}{ TSK-11 ${ }^{\mathrm{a}}$} & $20.33 \pm 6.45$ & $24.27 \pm 5.86$ & $29.33 \pm 5.51$ & a) & $5.06^{* *}(1.31 ; 8.82) d=-.88$ & $<.001^{* *}$ \\
\hline & & & & b) & $3.93^{*}(.18 ; 7.69) d=.63$ & \\
\hline & & & & c) & $9.00^{* *}(5.24 ; 12.76) d=1.50$ & \\
\hline
\end{tabular}

3 Values are presented as mean \pm standard deviation. RMDQ: Roland-Morris Disability Questionnaire; HAD_A:

4 Anxiety; HAD_D: Depression; TSK-11: Tampa Scale of Kinesiophobia.

5 a One-way analysis of variance

$6 \quad \mathrm{~b}$ Independent Student's $\mathrm{t}$ test.

7 q value; False Discovery Rate Correction

$8{ }^{*} q<.05 ;{ }^{* *} q<.01$. 


\section{Table 4 (on next page)}

Pearson Correlation coefficient for all variables in patients group.

VAS: Visual Analogue Scale; PPSA: Percentage Pain Surface Area; WP: Widespread Pain;

RMDQ: Roland-Morris Disability Questionnaire; TSK-11; Tampa Scale of Kinesiophobia; ;

HAD_D: Depression,HAD_A: Anxiety; ROMFE: Range of movement in Flexoextension; ROMLF:

Range of movement in lateral flexion; CRD L (\%): Composite Reach Distance Left (\%); CRD R

(\%): Composite Reach Distance Right (\%). ${ }^{\mathrm{a}} p<.05 .{ }^{\mathrm{aa}} p<.01$. 
1 Table 4. Pearson Correlation coefficient for all variables in patients group.

\begin{tabular}{|c|c|c|c|c|c|c|c|c|c|c|c|c|c|c|c|c|}
\hline & $\begin{array}{l}\text { Months } \\
\text { of pain }\end{array}$ & $\begin{array}{l}\text { Days } \\
\text { of pain } \\
\text { /month }\end{array}$ & $\begin{array}{l}\text { Days of } \\
\text { medication } \\
\text { /month }\end{array}$ & VAS & PPSA & WP & RMQD & $\begin{array}{l}\text { TSK- } \\
11\end{array}$ & HAD_D & HAD_A & TPD & ROMFE & ROMLF & $\begin{array}{l}\text { CRD R } \\
(\%)\end{array}$ & $\begin{array}{l}\text { CRD L } \\
(\%)\end{array}$ & GROUP \\
\hline \multirow[t]{2}{*}{ PPSA } & .091 & .298 & .274 & .142 & 1 & $.925^{\mathrm{aa}}$ & .092 & .268 & $.428^{\mathrm{a}}$ & .072 & .259 & $-.391^{\mathrm{a}}$ & -.288 & $-.488^{\mathrm{aa}}$ & $-.498^{\mathrm{aa}}$ & Care seekers \\
\hline & .161 & .222 & .176 & .137 & 1 & $.909^{\text {aа }}$ & .028 & .012 & .262 & .157 & .037 & -.159 & -.240 & -.001 & -.009 & $\begin{array}{l}\text { Non care } \\
\text { seekers }\end{array}$ \\
\hline \multirow[t]{2}{*}{ WP } & .007 & .120 & $.393^{\mathrm{a}}$ & .112 & $.925^{\mathrm{aa}}$ & 1 & .104 & .163 & $.436^{\mathrm{a}}$ & .191 & .286 & -.352 & -.280 & $-.540^{\text {aa }}$ & $-.564^{\mathrm{aa}}$ & Care seekers \\
\hline & .219 & .209 & .161 & .218 & $.909^{\mathrm{aa}}$ & 1 & .182 & .000 & .282 & .191 & .073 & -.081 & -.312 & -.126 & -.110 & $\begin{array}{l}\text { Non care } \\
\text { seekers }\end{array}$ \\
\hline
\end{tabular}

2 VAS: Visual Analogue Scale; PPSA: Percentage Pain Surface Area; WP: Widespread Pain; RMDQ: Roland-Morris Disability Questionnaire;

3 TSK-11; Tampa Scale of Kinesiophobia; ; HAD_D: Depression,HAD_A: Anxiety; ROMFE: Range of movement in Flexoextension; ROMLF:

4 Range of movement in lateral flexion; CRD L (\%): Composite Reach Distance Left (\%); CRD R (\%): Composite Reach Distance Right (\%).

$5 \quad{ }^{\mathrm{a}} p<.05$

$6 \quad{ }^{\text {aa }} p<.01$. 


\section{Table 5 (on next page)}

Table 5. Regression model for PPSA and WP in care seekers group with non-specific CLBP.

CLBP: Chronic Low Back Pain; VIF: Variance Inflation Factor; PPSA: Percentage Pain Surface Area; WP: Widespread Pain; HAD_D: Depression; ROM FE: Range of movement in

Flexoextension; CRD L (\%): Composite Reach Distance Left (\%); CRD R (\%): Composite Reach Distance Right (\%). ap $<.05$. aap $<.01$. 
1 Table 5. Regression model for PPSA and WP in care seekers group with non-specific CLBP.

\begin{tabular}{|c|c|c|c|c|c|}
\hline Care seekers & \multicolumn{5}{|l|}{ Overall model } \\
\hline \multirow[t]{7}{*}{ PPSA } & \multicolumn{5}{|c|}{$\mathrm{R}^{2}=.391$, adjusted $\mathrm{R}^{2}=.346, \mathrm{~F}=8.67$} \\
\hline & $\begin{array}{l}\text { Predictor } \\
\text { variables }\end{array}$ & $\begin{array}{l}\text { Regression coefficient } \\
\text { (B) }\end{array}$ & $\begin{array}{l}\text { Standardized } \\
\text { coefficient }(\beta)\end{array}$ & P-value & VIF \\
\hline & CRD L (\%) & -.261 & -.458 & $.005^{\text {aa }}$ & 1.01 \\
\hline & HAD_D & .747 & .297 & $.018^{\mathrm{a}}$ & 1.01 \\
\hline & \multicolumn{5}{|c|}{ Excluded variables } \\
\hline & CRD R (\%) & & .011 & .980 & 7.69 \\
\hline & $\begin{array}{l}\text { Days of medicatic } \\
\text { /month }\end{array}$ & & .230 & .133 & 1.02 \\
\hline \multirow[t]{7}{*}{ WP } & \multicolumn{5}{|c|}{$\mathrm{R}^{2}=.502$, adjusted $\mathrm{R}^{2}=.485, \mathrm{~F}=28.60$} \\
\hline & $\begin{array}{l}\text { Predictor } \\
\text { variables }\end{array}$ & $\begin{array}{l}\text { Regression coefficient } \\
\text { (B) }\end{array}$ & $\begin{array}{l}\text { Standardized } \\
\text { coefficient }(\beta)\end{array}$ & P-value & VIF \\
\hline & CRD L (\%) & -.325 & -.394 & $<.001^{\text {aa }}$ & 1.51 \\
\hline & ROM FE & -.187 & -.197 & $.037^{\mathrm{a}}$ & 1.47 \\
\hline & HAD_D & 1.27 & .347 & $<.001^{\text {aa }}$ & 1,08 \\
\hline & \multicolumn{5}{|c|}{ Excluded variables } \\
\hline & CRD R (\%) & & -.047 & .885 & 17.92 \\
\hline
\end{tabular}

2 CLBP: Chronic Low Back Pain; VIF: Variance Inflation Factor; PPSA: Percentage Pain Surface Area;

3 WP: Widespread Pain; HAD_D: Depression; ROM FE: Range of movement in Flexoextension; CRD L

4 (\%): Composite Reach Distance Left (\%); CRD R (\%): Composite Reach Distance Right (\%).

5 ap $<.05$.

6 aap $<.01$. 
Figure 1

Figure 1. Expansion of pain in patients who sought care. 

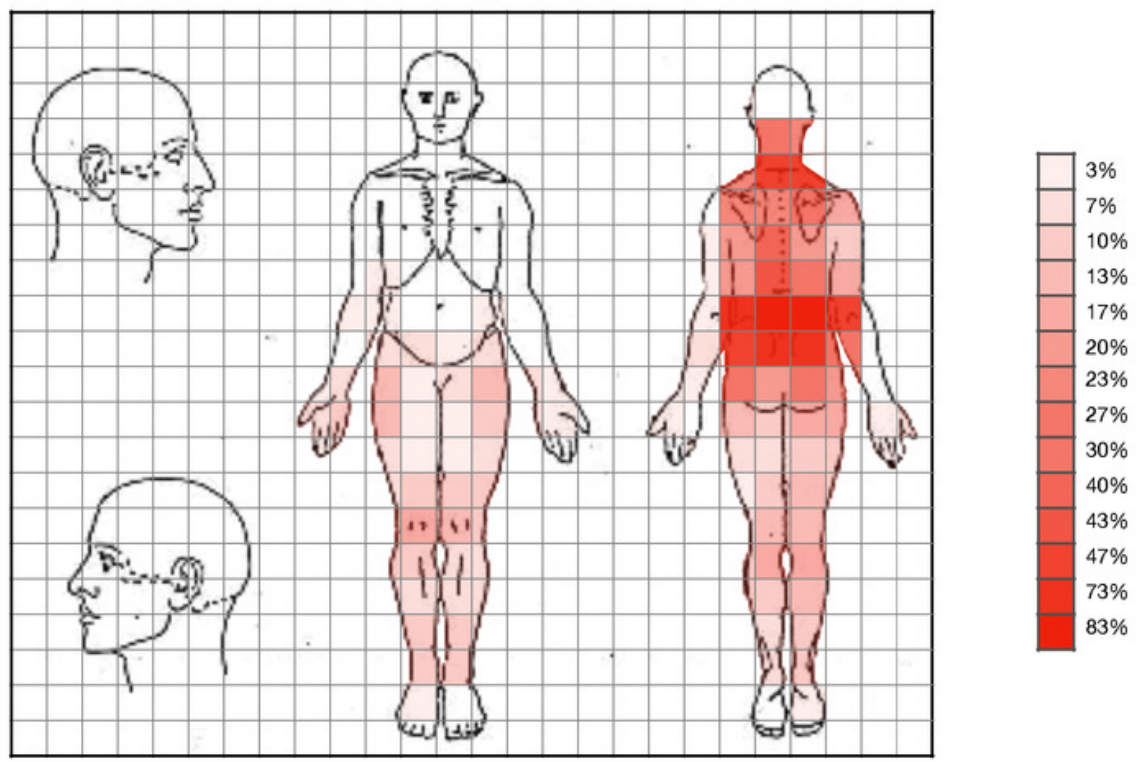
Figure 2

Figure 2. Expansion of pain in patients who did not seek care. 

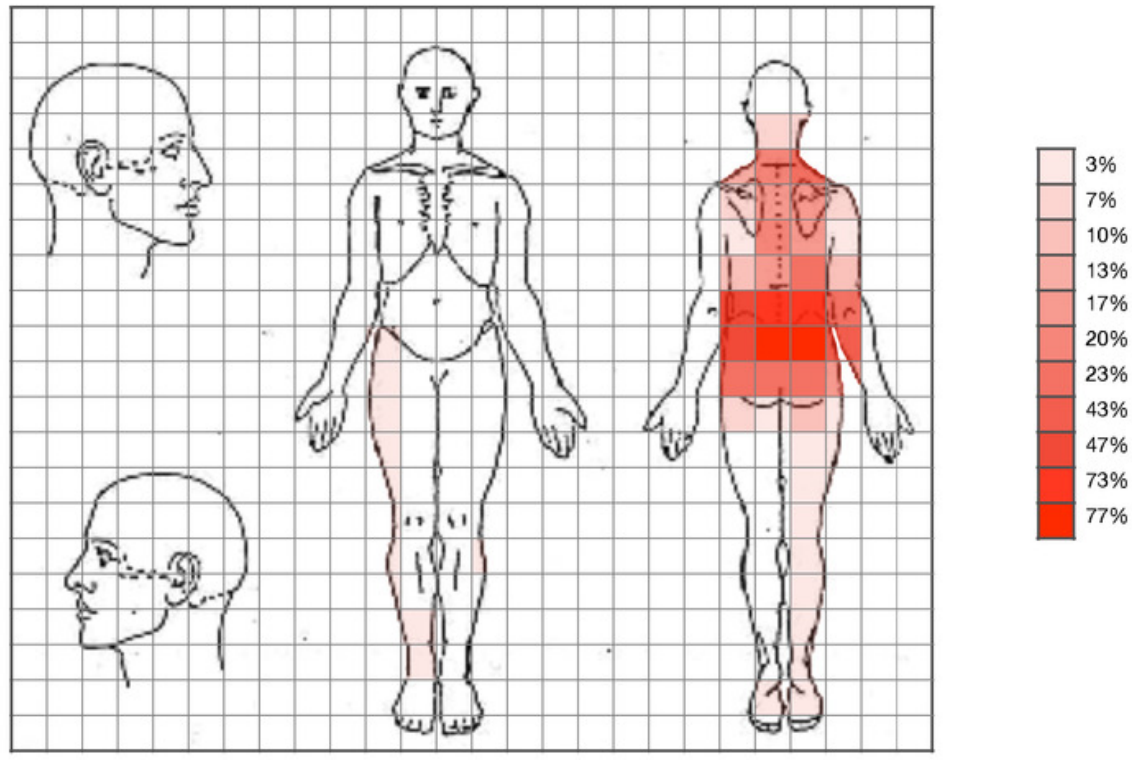
Figure 3

Scatter plot for PPSA.

$q<0.05$

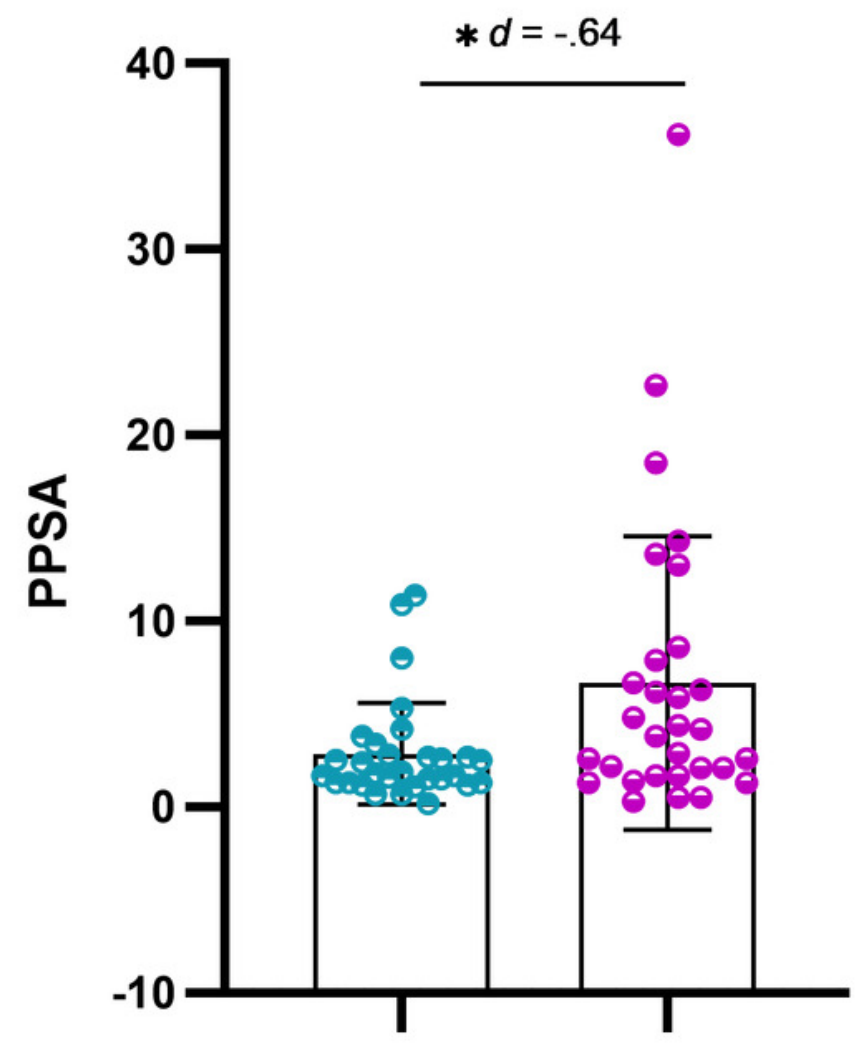

- Non-care seekers

- $\quad$ Care seekers 
Figure 4

Scatter plot for WP.

$q<0.05$

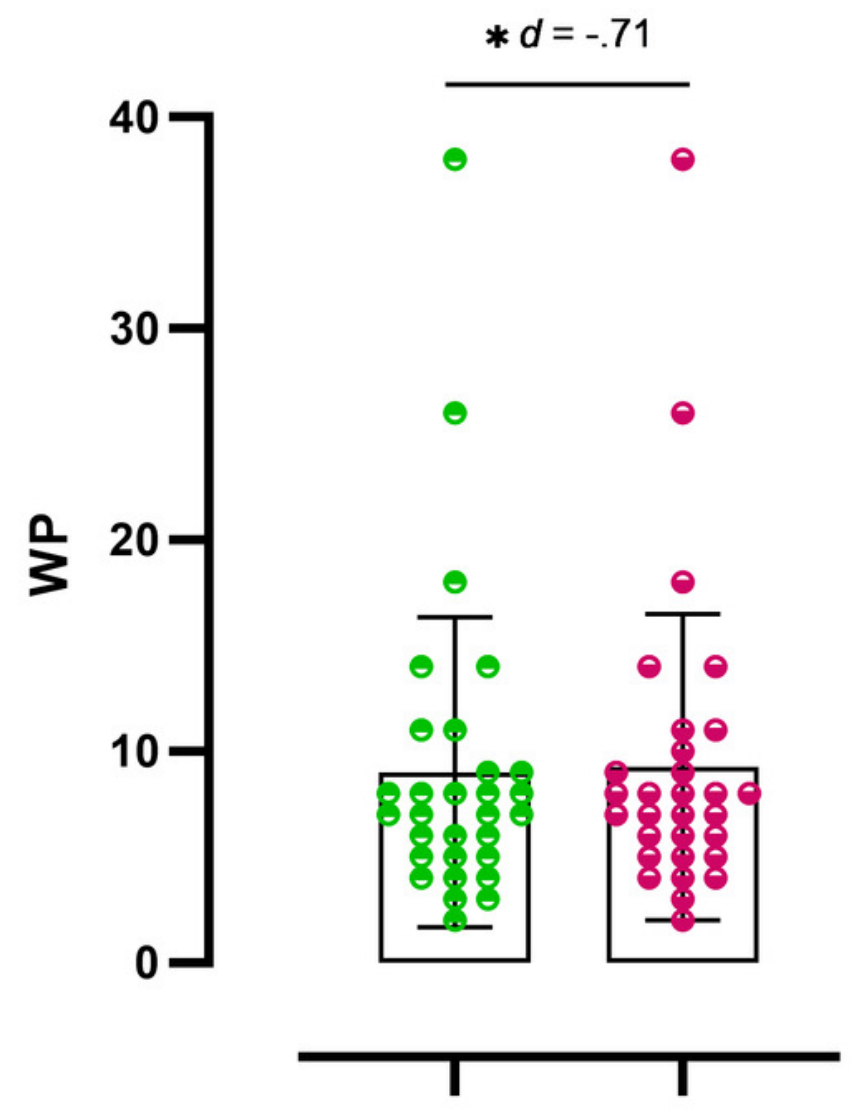

- Non-care seekers

- $\quad$ Care seekers 